\title{
Myasthenia gravis during pregnancy: what care should be taken?
}

\author{
Miastenia gravis durante a gestação: quais cuidados devem ser realizados? \\ Renata Dal-Prá DUCCl', Cláudia Suemi Kamoi KAY', Otto Jesus Hernandez FUSTES', \\ Lineu Cesar WERNECK', Paulo José LORENZONI', Rosana Herminia SCOLA'
}

\begin{abstract}
Myasthenia gravis (MG) is an autoimmune disease in which the peak incidence is among women of childbearing age. For this reason, there is an overlap between the occurrence of this disease and pregnancy. It is known that MG symptoms can worsen during pregnancy and postpartum, and that pregnancy has special characteristics in MG patients. Children born to myasthenic mothers are at risk of having transient neonatal myasthenia. We briefly review the main relationships between MG and pregnancy, and we make recommendations for MG therapy, pregnancy, delivery, breastfeeding and newborns.
\end{abstract}

Keywords: Myasthenia gravis; Pregnancy; Delivery; Breastfeeding; Transient Neonatal Myasthenia; Therapy.

RESUMO

Miastenia gravis (MG) é uma doença autoimune cujo pico de incidência nas mulheres coincide com a idade fértil. Por esse motivo, existe uma sobreposição entre a ocorrência desta doença com a gestação. Sabe-se que os sintomas da MG podem piorar durante a gestação e no puerpério, e que a gestação possui características especiais em pacientes com MG. Existe também um risco de miastenia neonatal transitória em recém-nascidos de gestantes miastênicas. Nós revisamos brevemente as principais relações entre MG e gestação, e realizamos recomendações para o tratamento da MG durante a gestação, os cuidados durante a gravidez, incluindo a via de parto, e com o recém-nascido e com a amamentação.

Palavras-chaves: Miastenia gravis; Gestação; Via de parto; Amamentação; Miastenia Neonatal Transitória;Tratamento.

\section{INTRODUCTION}

Myasthenia gravis (MG) is an autoimmune disorder that is caused by antibodies against the neuromuscular junction. Its main characteristic is extraocular and proximal muscle weakness associate with fatigability ${ }^{1,2}$. The peak incidence of MG in women coincides with childbearing age ${ }^{3-5}$. Prenatal counseling should be provided to all MG patients who are women in the reproductive age group. MG does not affect patients' fertility ${ }^{2}$, but it does interfere with family planning ${ }^{4}$. Many patients have abstained from having children mainly because of fear of the possible effects of MG medications on the development of the unborn child ${ }^{4}$. Thus, questions have arisen concerning the impact of MG on pregnancy, as well as of pregnancy on MG; and concerning the effect of medications used to treat MG on fetal development, mode of delivery, safety of breastfeeding and newborn care.

In this brief review, we describe the main relationship between MG and pregnancy and we make recommendations for MG therapy, pregnancy, delivery, breastfeeding and newborns.

\section{THE EFFECT OF PREGNANCY ON MYASTHENIA GRAVIS}

In $12 \%$ to $15 \%$ of women with MG, the first manifestations of the disease were during pregnancy or in the postpartum

1Universidade Federal do Paraná, Complexo Hospital de Clínicas, Serviço de Doenças Neuromusculares, Curitiba PR, Brazil.

Renata Dal-Prá DUCCI (iD http://orcid.org/0000-0002-1673-5074; Cláudia Suemi Kamoi KAY (D) http://orcid.org/0000-0003-0173-0809; Otto Jesus Hernandez FUSTES (ID http://orcid.org/0000-0003-0778-5376; Lineu Cesar WERNECK (iD http://orcid.org/0000-0003-1921-1038;

Paulo José LORENZONI (D) http://orcid.org/0000-0002-4457-7771; Rosana Herminia SCOLA (D) http://orcid.org/0000-0002-3957-5317

Correspondence: Renata Dal-Prá Ducci; Email: renata.ducci@hc.ufpr.br.

Conflict of interest: There is no conflict of interest to declare.

Authors' contributions: All authors worked extensively on the manuscript and all approved this submitted version. The authors Renata-Prá Ducci and Paulo José Lorenzoni conceived the idea for the article, which was written by Renata Dal-Prá Ducci and critically reviewed by all authors.

Received on September 28, 2020; Received in its final form October 16, 2020; Accepted on October 21, 2020. 
$\operatorname{period}^{6,7}$. A population-based case-control study indicated that women in the postpartum period were at higher risk of experiencing symptoms of MG, especially after the first pregnancy ${ }^{8}$. If a diagnosis of MG is suspected during pregnancy or the postpartum period, an investigation should be carried out in a similar way to that performed outside these periods (MG has the same diagnostic criteria during pregnancy as outside it). The main MG diagnostic tools are detection of serum antibodies (against acetylcholine receptor [AchR] and muscle-specific tyrosine kinase [MuSK], among others) and abnormalities in electrophysiological tests (repetitive nerve stimulation and single fiber electromyography $)^{5,9}$.

The view that pregnancy does not influence the evolution of MG over the long term seems to be well-established in the international literature ${ }^{6,7}$.

With regard to the effects of pregnancy on MG over the short term, the symptoms may improve, remain stable or worsen, and these effects can vary from pregnancy to pregnancy in the same patient ${ }^{2,7,10,11}$. In a Brazilian study, the condition of $50 \%$ of the patients worsened during pregnancy, mainly in the second trimester, and in the postpartum ${ }^{11}$. Other studies have suggested that the first trimester is also a critical period ${ }^{10,12}$. It is believed that the third trimester is a period of greater stability or even clinical improvement for these patients. This is perhaps the result of increased production of $\alpha$-fetoprotein, thus inducing physiological immunosuppression, since $\alpha$-fetoprotein is believed to be an effective inhibitor of AChR antibodies ${ }^{5,8,13}$. In contrast, the postpartum period would be the most critical because of the production of cytokines and immunoglobulins induced by estrogen and decreased levels of $\alpha$-fetoprotein, the risk of infection and the fatigue induced by stress and sleep deprivation related to the new family routine ${ }^{5,12,14,15}$. MG symptom exacerbations may occur even among patients with good control prior to conception $^{2,5,12}$. In a recent study, a myasthenic crisis during pregnancy was observed in less than $1 \%$, and all cases were correlated with occurrences of infections ${ }^{11}$. However, some authors have recommended that pregnancies should be planned such that they are no earlier than one to two years after MG have been diagnosed, since most exacerbations occur in the first year of illness ${ }^{2,5}$.

Most suspected thymomas are indolent and do not need emergency treatment. Moreover, thymectomy has little immediate effect. Hence, use of non-contrast chest tomography should be postponed until the postpartum period ${ }^{5,9}$.

\section{THE EFFECT OF MYASTHENIA GRAVIS ON PREGNANCY}

MG can have a number of effects on pregnancy. Currently, there is no evidence among pregnant women that presence of antibodies against MuSK has greater impact on pregnancy or greater risk of worsened myasthenic symptoms than does presence of antibodies against $\mathrm{AChR}^{16}$. Retrospective studies have also demonstrated that prior thymectomy had no effect on myasthenia symptoms during pregnancy ${ }^{11,17}$.

Several studies have shown a higher rate of preterm premature rupture of amniotic membranes (PPROM) and prematurity, possibly associated with use of corticosteroids ${ }^{6,10,18}$. The abortion rate is similar to that of the general population and is not influenced by MG treatment ${ }^{5}$. Among the possible complications of pregnancy, preeclampsia occurs in $6-8 \%$ of all pregnancies ${ }^{19}$. An association between preeclampsia and $\mathrm{MG}$ is rare, but management of such cases is challenging ${ }^{20}$. Hypertension should be treated with methyldopa and oral hydralazine. If systolic pressure is greater than $160 \mathrm{mmHg}$ or diastolic pressure is greater than $110 \mathrm{mmHg}$, intravenous hydralazine is indicated. Beta blockers and calcium channel blockers should be avoided due to the potential risk of worsening MG symptoms ${ }^{19,20}$. Magnesium sulphate is the gold standard therapy for eclampsia and severe preeclampsia; however, it should not be used in myasthenic patients because it inhibits presynaptic calcium influx at the neuromuscular junction ${ }^{19-21}$. Options for preventing seizures include levetiracetam and valproic acid, but the latter should be avoided in cases of major hepatic impairment. For refractory cases, use of phenytoin may be indicated, although there is a theoretical risk of exacerbating myasthenic weakness by reducing the sensitivity of acetylcholine receptors ${ }^{19-21}$. Benzodiazepines can be used for seizure control with caution, due to muscle relaxant effects via central potentiation of gamma amino butyric acid (GABA) release ${ }^{19}$.

The delivery route in these patients needs to be an obstetric indication ${ }^{2,15,22}$. In other words, the diagnosis of MG does not contraindicate normal delivery per se. This is because the myometrial muscle is composed of smooth muscle and is not affected by MG autoantibodies ${ }^{2}$. Patients may worsen in the second stage of labor when the striated muscles are involved and, at that time, maternal exhaustion may require use of forceps or vacuum extraction ${ }^{2}$. Studies have shown cesarean rates ranging from $11 \%$ to $78.3 \%^{11,12,16,18,23-25}$. In a national study, the prevalence of caesarean section was $75 \%$, although this figure may have been influenced by the high rates of cesarean sections in Brazil ${ }^{11}$. There is no correlation between the route of delivery and the occurrence of MG decompensation in the postpartum ${ }^{16,22}$.

It is important to note that local, spinal and epidural anesthesia are safe. If general anesthesia is necessary, care needs to be taken with use of neuromuscular blockers ${ }^{2,15,22}$. In a small series of cases, epidural labor delivery analgesia associated with instrumentation (vacuum delivery) was shown to be a good option for circumventing the effects of maternal fatigue on delivery, especially when the parturient had significant muscle weakness, thereby increasing spontaneous vaginal deliver ${ }^{26}$. Postoperative pain management can consist of 
use of non-opioid drugs such as acetaminophen and nonsteroidal anti-inflammatory. Use of opioid/narcotic analgesics such as tramadol or morphine should be avoided due to the possible risk of respiratory depression ${ }^{18}$.

\section{THERAPEUTIC POSSIBILITIES FOR MYASTHENIA GRAVIS DURING PREGNANCY}

Ideally, treatment for pregnant myasthenic patients should consist of use of corticosteroids and pyridostigmine $e^{5,9,27}$. If possible, pregnancy planning should be implemented, with enough time to assess the risks and benefits of each medication and to make therapeutic changes. New drugs should preferably not be started during pregnancy ${ }^{5,9,10}$. Breastfeeding, on the other hand, should be stimulated, although it should be avoided at the peak of the medication dose $\mathrm{e}^{5,10}$.

Pyridostigmine is an anticholinesterase agent that is used for symptomatic management of $\mathrm{MG}^{10,27}$. There are no reports of fetal malformations, and breastfeeding is safe ${ }^{5}$.

Corticosteroids have been used for many years in pregnant women with other diseases. Their use has been correlated with increased risk of cleft palate (in a single study in which they were applied in the first trimester of pregnancy) ${ }^{28}$, increased incidence of gestational diabetes, hypertensive disease during pregnancy, urinary tract infection and premature delivery ${ }^{29}$. The recommendation is to use the lowest possible dose, in an effort to achieve the minimal manifestation state. Corticosteroids are safe during breastfeeding, and there are no reports of adrenal suppression in newborns ${ }^{5,10}$.

Several studies on pregnant women with MG using azathioprine have already been carried out. For some authors, azathioprine is associated with prematurity, intrauterine growth retardation and higher risk of teratogenesis (prevalence between $0 \%$ and $11.8 \%$ ). However, others have reported that azathioprine is safe during pregnancy and during breastfeeding, and they have stated that it should be the immunosuppressant drug of choice, after corticosteroids, in cases of MG during pregnancy ${ }^{5,29-31}$. Azathioprine is considered to be a safe drug for use during pregnancy in Europe, whereas it is still contraindicated in the United States and in Brazil ${ }^{9,29,32,33}$. It is known that the fetal liver does not produce pyrophosphorylase, the enzyme responsible for converting azathioprine into its active metabolites ${ }^{5,30}$.

Use of cyclosporine is associated with increased risk of gestational diabetes, gestational hypertensive disease, prematurity and low birth weight. However, this drug is considered safe during breastfeeding, according to some authors ${ }^{5,34}$.

Use of tacrolimus is also associated with a higher risk of prematurity and low birth weight, with divergent results in relation to teratogenesis ${ }^{5,35}$. An in vitro study suggested that there was higher risk of teratogenesis if tacrolimus was used in association with prednisolone ${ }^{34}$. Some authors have stated that breastfeeding should be avoided by patients who are using this medication ${ }^{5}$.

Other immunosuppressive drugs should be discontinued during pregnancy and the breastfeeding period (e.g. mycophenolate mofetil, methotrexate and cyclophosphamide). Both mycophenolate mofetil and methotrexate must be discontinued due to the increased risk of miscarriage and teratogenesis. Mycophenolate mofetil should be suspended and replaced ideally six weeks before the patient becomes pregnant, while methotrexate should be suspended and replaced three months before pregnancy ${ }^{5,29}$. Breastfeeding is not recommended while using either of these medications ${ }^{5,29,36}$. Similarly, cyclophosphamide must be avoided during pregnancy due to the risk of teratogenesis; breastfeeding is also contraindicated $^{29,36}$. Cyclophosphamide should be suspended and replaced one year before pregnancy ${ }^{29}$.

There are few case reports regarding the use of rituximab in pregnant women. It has been suggested that there should be an interval of 12 months between the last dose of rituximab and pregnancy ${ }^{5,37}$. Breastfeeding is not recommended because of a lack of data on the possible effects of this drug $g^{5,37}$. Eculizumab should be avoided during pregnancy and breastfeeding for the same reason ${ }^{38}$.

Ifamyastheniccrisisoccurs, bothimmunoglobulinandplasmapheresis appear to be safe. There are studies on myasthenic pregnant patients who used immunoglobulin without complications, including as maintenance monotherapy ${ }^{2,5,39}$. With regard to therapeutic plasma exchange (TPE), studies have mainly been conducted on pregnant women with other diseases. However, a recent study on 57 pregnancies, among which three were myasthenic, showed that therapeutic apheresis was well tolerated ${ }^{40}$. There is a tendency to prefer immunoglobulin in such cases due to the possibility of hypotension during the $\mathrm{TPE}^{2,5}$. If TPE is chosen, some precautions should be taken, such as: positioning the patient in the left lateral position to avoid compression of the inferior vena cava; adjustment of plasma volume in the second and third trimesters of pregnancy to compensate for the increase in maternal blood volume; the volume of blood in extracorporeal circulation should not decrease the blood volume by more than $10 \%$, in order to avoid hypotension; preventing and monitoring for hypocalcemia; monitoring the levels of fibrinogen, because a decrease carries a greater risk of bleeding (and for that reason a minimum 24-hour interval between the last plasmapheresis session and the cesarean delivery is suggested); and determination of Rh status and consideration of possible RhIg readministration after TPE, if necessary ${ }^{41,42}$.

Table 1 indicates the main drugs used in treating MG, in relation to their safety profile for pregnancy and breastfeeding ${ }^{2,29,32,33,36,38}$. It is also important to advise MG patients on the medications that are contraindicated due to $\mathrm{MG}$ (Table 2) 2,29,32,33,36,43. 
Table 1. Risk categories of medications used to treat myasthenia gravis during pregnancy and breastfeeding.

\begin{tabular}{lll}
\hline Drugs & FDA pregnancy category & \\
\hline Azathioprine & D & $\begin{array}{l}\text { Conflicting results; to be used with caution, as specified by the Brazilian } \\
\text { Ministry of Health }\end{array}$ \\
Cyclophosphamide & D & Not advised \\
Cyclosporine & C & $\begin{array}{l}\text { Conflicting results; to be used with caution, as specified by the Brazilian } \\
\text { Ministry of Health }\end{array}$ \\
Eculizumab & C & Not advised because of lack of information \\
Immunoglobulins & C & Allowed \\
Methotrexate & X & Not advised \\
Mycophenolate mofetil & D & Not advised \\
Pyridostigmine & C & Allowed \\
Rituximab & C & Not advised because of lack of information \\
Corticosteroids & C & Allowed \\
Tacrolimus & C & Conflicting results; to be used with caution, as specified by the Brazilian \\
\hline
\end{tabular}

FDA: United States Food and Drug Administration; D: positive evidence of risk; C: risk cannot be ruled out; X: contraindicated in pregnancy.

Table 2. Medications contraindicated for patients with myasthenia gravis.

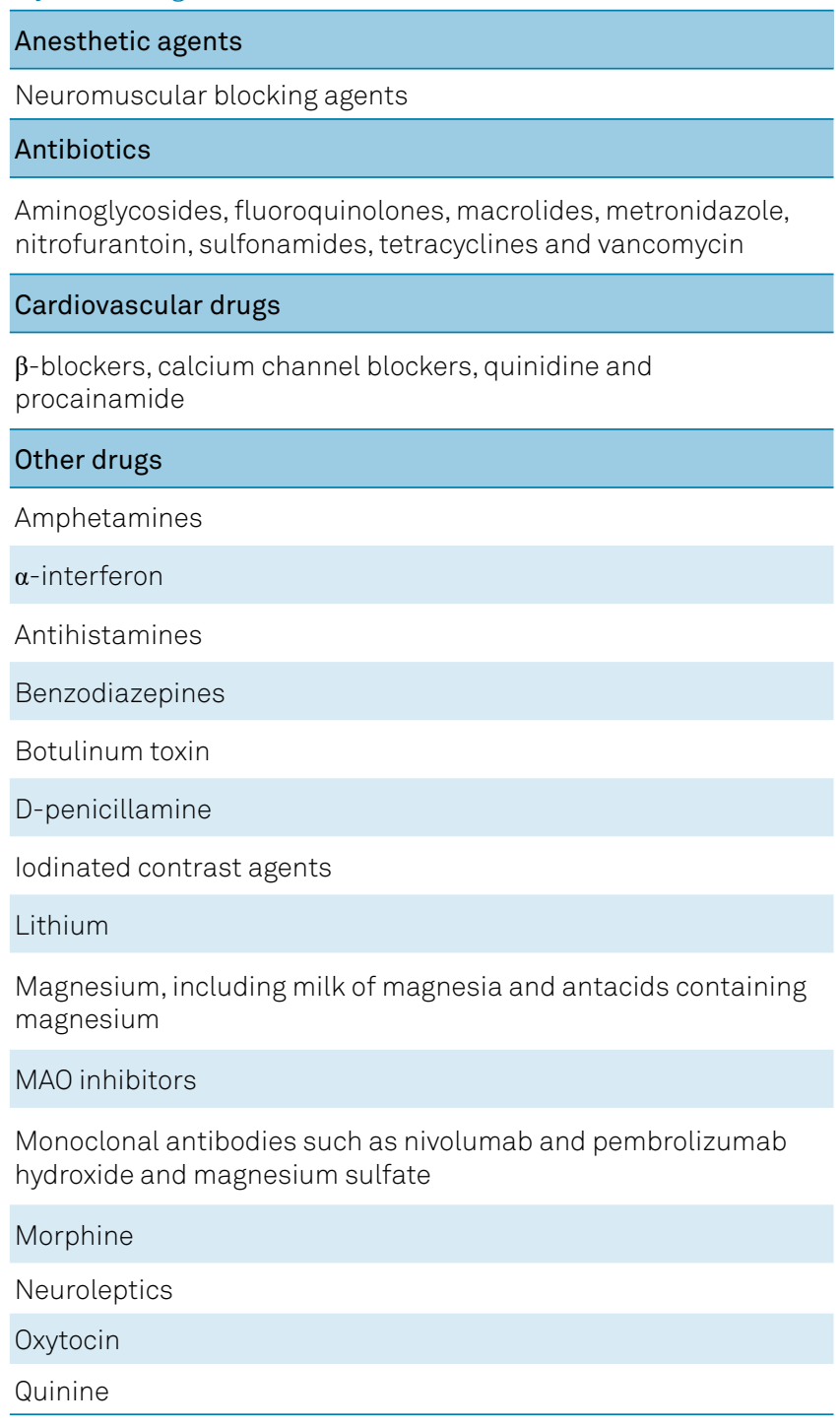

Other drugs have been reported to exacerbate MG. The risks and benefits of starting a new medication must be considered carefully in relation to these patients, who should be followed up closely.

\section{RISKS FOR NEWBORNS FROM MYASTHENIC MOTHERS}

With regard to newborns, the main complication is a higher risk of premature birth ${ }^{6,11}$. In MG, because of the antibodies against AChR, transient neonatal MG (TNMG) occurs at rates ranging from 10 to $20 \%$. This does not relate to either maternal MG status or maternal AChR antibody concentration $^{2}$. It means that asymptomatic pregnant women are also at risk of having newborns with TNMG and, on the other hand, that most pregnant women with severe MG will have newborns without TNMG. It is believed that the occurrence of TNMG depends not only on maternal antibody levels, but also on antibody transportation across the placenta, antibodies binding to the child's postsynaptic muscle membrane and safety factors in the neuromuscular junction ${ }^{31}$. In addition, there have also been reports of TNMG in newborns from MG mothers with antibodies against MUSK and lipoprotein receptor-related protein 4 (LRP4), and also in antibody-negative MG patients ${ }^{31,44,45}$. Some studies have suggested that TNMG occurrence is lower when the pregnant woman has previously undergone thymectomy $y^{5,7,24}$.

In most cases of TNMG, the newborn shows symptoms of hypotonia, ptosis, ophthalmoparesis and bulbar and respiratory weakness from within 12 hours after birth to several days later ${ }^{2}$. TNMG develops as a result of maternal IgG antibodies that cross the placental barrier. The delay in onset 
of symptoms is due to clearance of the anticholinesterase agents taken by the mother. The diagnosis is clinical and does not require measurement of autoantibodies or electrophysiological studies in the newborn ${ }^{15}$. Symptoms can persist for periods from two weeks to months, and $90 \%$ recover within two months. Treatment consists of support in mild to moderate cases and immunoglobulin or plasmapheresis in severe cases. Cases of arthrogryposis and fetal AChR inactivation syndrome have been also reported, but both of these syndromes are rare. They are caused by the mother's antibodies against fetal-type $\mathrm{AChR}^{5,10,31,45-47}$.

It is important to emphasize that breastfeeding, provided that it is not contraindicated by any medications being taken by the puerperal woman, is not contraindicated, even in cases of TNMG, arthrogryposis or fetal AChR inactivation syndrome. This recommendation is based on the fact that the level of maternal IgG antibodies in breast milk comprises only $2 \%$ of the serum level, and that an even smaller proportion is absorbed by the child ${ }^{31,48}$. Some studies have suggested that the breastfeeding schedule should not coincide with the peak serum concentration of the medications used by the mother ${ }^{5,49}$.

\section{RECOMMENDATIONS}

The main recommendation is that prenatal counseling should be provided for all MG patients who are women in the reproductive age group. Preferably, these patients should use pyridostigmine and corticosteroids during pregnancy; use of mycophenolate, cyclophosphamide and methotrexate should be discontinued. Delivery needs to be carried out in accordance with obstetric rules. Anesthesia (epidural, spinal or local) is safe during delivery. Some drugs (e.g. neuromuscular blockers, oxytocin and magnesium sulfate) should not be administered to $\mathrm{MG}$ patients. The pediatric team needs to be prepared for the risk of transient neonatal MG. The family should be alerted to the possibility that MG could worsen in the postpartum period. Breastfeeding should be encouraged in most cases. Lastly, it should be noted that, despite all the above warnings, there is no increased risk of maternal or perinatal mortality among pregnant women with MG and, therefore, pregnancy plans should not, in most cases, be discouraged, provided that there is adequate monitoring of the patients.

\section{REFERENCES}

1. Cunha FM, Scola RH, Werneck LC. Myasthenia Gravis: clinical evaluation of 153 patients. Arq Neuropsiquiatr. 1999 Jun;57(2B):457-64. https://doi.org/10.1590/S0004282X1999000300018

2. Waters J. Management of Myasthenia Gravis in Pregnancy. Neurol Clin. 2019 Feb;37(1):113-20. https://doi.org/10.1016/j. ncl.2018.09.003

3. Aguiar A de AX, Carvalho AF, Costa CM de C, et al. Myasthenia gravis in Ceará, Brazil: clinical and epidemiological aspects. Arq Neuropsiquiatr. 2010 Dec;68(6):843-8. https://doi.org/10.1590/ S0004-282X2010000600003

4. Ohlraun S, Hoffmann S, Klehmet J, et al. Impact of myasthenia gravis on family planning: How do women with myasthenia gravis decide and why? Muscle Nerve. 2015 Sep;52(3):371-9. https://doi. org/10.1002/mus.24556

5. Hamel J, Ciafaloni E. An Update: Myasthenia Gravis and Pregnancy. Neurol Clin. 2018 May;36(2):355-65. https://doi.org/10.1016/j. ncl.2018.01.005

6. Hoff JM, Daltveit AK, Gilhus NE. Myasthenia gravis: consequences for pregnancy, delivery, and the newborn. Neurology. 2003 Nov 25;61(10):1362-6. https://doi.org/10.1212/01. WNL.0000082725.21444.EC

7. Hoff JM, Daltveit AK, Gilhus NE. Myasthenia gravis in pregnancy and birth: identifying risk factors, optimising care. Eur J Neurol. 2007 Jan;14(1):38-43. https://doi.org/10.1111/j.1468-1331.2006.01538.x

8. Boldingh MI, Maniaol AH, Brunborg C, et al. Increased risk for clinical onset of myasthenia gravis during the postpartum period. Neurology. 2016 Nov 15;87(20):2139-45. https://doi.org/10.1212/ WNL.0000000000003339

9. Sanders DB, Wolfe GI, Benatar M, et al. International consensus guidance for management of myasthenia gravis: Executive summary. Neurology. 2016 Jul 26;87(4):419-25. https://doi.org/10.1212/ WNL.0000000000002790
10. Ciafaloni E, Massey JM. Myasthenia gravis and pregnancy. Neurol Clin. 2004 Nov;22(4):771-82.

11. Ducci RD, Lorenzoni PJ, Kay CS, et al. Clinical follow-up of pregnancy in myasthenia gravis patients. Neuromuscul Disord. 2017 Apr;27(4):352-7. https://doi.org/10.1016/j.nmd.2017.01.021

12. Batocchi AP, Majolini L, Evoli A, et al. Course and treatment of myasthenia gravis during pregnancy. Neurology. 1999 Feb;52(3):44752. https://doi.org/10.1212/WNL.52.3.447

13. Brenner T, Beyth Y, Abramsky O. Inhibitory effect of alpha-fetoprotein on the binding of myasthenia gravis antibody to acetylcholine receptor. Proc Natl Acad Sci USA. 1980 Jun;77(6):3635-9. https://doi. org/10.1073/pnas.77.6.3635

14. Varner M. Myasthenia gravis and pregnancy. Clin Obstet Gynecol. 2013 Jun;56(2):372-81. https://doi.org/10.1097/ GRF.0b013e31828e92c0

15. Norwood F, Dhanjal M, Hill M, et al. Myasthenia in pregnancy: best practice guidelines from a U.K. multispecialty working group. J Neurol Neurosurg Psychiatry. 2014 May;85(5):538-43. https://doi. org/10.1136/jnnp-2013-305572

16. Braga AC, Pinto C, Santos E, Braga J. Myasthenia gravis in pregnancy: Experience of a portuguese center. Muscle Nerve. 2016 Oct;54(4):715-20. https://doi.org/10.1002/mus.25095

17. Roth TC, Raths J, Carboni G, et al. Effect of pregnancy and birth on the course of myasthenia gravis before or after transsternal radical thymectomy. Eur J Cardiothorac Surg. 2006 Feb;29(2):231-5. https:// doi.org/10.1016/j.ejcts.2005.11.022

18. Tanacan A, Fadiloglu E, Ozten G, et al. Myasthenia gravis and pregnancy: retrospective evaluation of 27 pregnancies in a tertiary center and comparison with previous studies. Ir J Med Sci. 2019 Nov;188(4):1261-7. https://doi.org/10.1007/s11845-019-02029-0

19. Hassan A. Myasthenia gravis and preeclampsia: Dot all the l's and cross all the T's. J Taibah Univ Med Sci. 2017 May 5;12(5):461-4. https://doi.org/10.1016/j.jtumed.2017.01.006 
20. Ozcan J, Balson IF, Dennis AT. New diagnosis myasthenia gravis and preeclampsia in late pregnancy. BMJ Case Rep. 2015 Feb 26;2015:bcr2014208323. https://doi.org/10.1136/bcr-2014-208323

21. Sikka P, Joshi B, Aggarwal N, et al. Distinguishing Myasthenia Exacerbation from Severe Preeclampsia: A Diagnostic and Therapeutic Challenge. J Clin Diagn Res. 2015 Aug;9(8):QD05-6. https://doi.org/10.7860/JCDR/2015/12789.6357

22. Ferrero S, Pretta S, Nicoletti A, et al. Myasthenia gravis: management issues during pregnancy. Eur J Obstet Gynecol Reprod Biol. 2005 Aug 1;121(2):129-38. https://doi.org/10.1016/j.ejogrb.2005.01.002

23. Mitchell PJ, Bebbington M. Myasthenia gravis in pregnancy. Obstet Gynecol. 1992 Aug;80(2):178-81.

24. Djelmis J, Sostarko M, Mayer D, Ivanisevic M. Myasthenia gravis in pregnancy: report on 69 cases. Eur J Obstet Gynecol Reprod Biol. 2002 Aug 5;104(1):21-5.

25. Téllez-Zenteno JF, Hernández-Ronquillo L, Salinas V, et al. Myasthenia gravis and pregnancy: clinical implications and neonatal outcome. BMC Musculoskelet Disord. 2004 Nov 16;5:42. https://doi. org/10.1186/1471-2474-5-42

26. Tsurane K, Tanabe S, Miyasaka N, et al. Management of labor and delivery in myasthenia gravis: A new protocol. J Obstet Gynaecol Res. 2019 May;45(5):974-80. https://doi.org/10.1111/jog.13922

27. Edmundson C, Guidon AC. Neuromuscular Disorders in Pregnancy. Semin Neurol. 2017 Dec;37(6):643-52. https://doi. org/10.1055/s-0037-1608785

28. Rodriguez-Pinilla E, Martinez-Frias ML. Corticosteroids during pregnancy and oral clefts: a case-control study. Teratology. 1998 Jul;58(1):2-5. https://doi.org/10.1002/(SICl)10969926(199807)58:1<2::AID-TERA2>3.0.CO;2-4

29. Bansal R, Goyal MK, Modi M. Management of myasthenia gravis during pregnancy. Indian J Pharmacol. 2018 Nov-Dec;50(6):302-8. https://doi.org/10.4103/ijp.IJP_452_17

30. Polifka JE, Friedman JM. Teratogen update: azathioprine and 6-mercaptopurine. Teratology. 2002 May;65(5):240-61. https://doi. org/10.1002/tera.10043

31. Gilhus NE, Hong Y. Maternal myasthenia gravis represents a risk for the child through autoantibody transfer, immunosuppressive therapy and genetic influence. Eur J Neurol. 2018 Dec;25(12):1402-9. https:// doi.org/10.1111/ene.13788

32. US Food \& Drug Administration. Pregnancy categories, drug safety and availability. [Internet] US Food \& Drug Admnistration; 2020 [cited 2020 Feb 15]. Available from: https://www.fda.gov/Drugs/default.htm

33. Ministério da Saúde. Resolução da Diretoria Colegiada - RDC No 60, de 17 de dezembro de 2010. [Internet]. Agência Nacional de Vigilância Sanitária; 2010 [cited 2020 May 2]. 69p. Available from: http://bvsms. saude.gov.br/bvs/saudelegis/anvisa/2010/rdc0060_17_12_2010.pdf

34. Dogan NU, Uysal II, Fazliogullari Z, et al. Investigation of developmental toxicity and teratogenicity of cyclosporine A, tacrolimus and their combinations with prednisolone. Regul Toxicol Pharmacol. 2016 Jun;77:213-22. https://doi.org/10.1016/j. yrtph.2016.03.010

35. Kainz A, Harabacz I, Cowlrick IS, et al. Review of the course and outcome of 100 pregnancies in 84 women treated with tacrolimus.
Transplantation. 2000 Dec 27;70(12):1718-21. https://doi. org/10.1097/00007890-200012270-00010

36. Ministério da Saúde; Secretaria da Atenção à Saúde; Departamento de Ações Programáticas e Estratégicas. Amamentação e uso de medicamentos e outras substâncias. 2nd ed. Brasília (DF): Ministério da Saúde; 2014.

37. Stieglbauer K, Pichler R, Topakian R. 10-year-outcomes after rituximab for myasthenia gravis: Efficacy, safety, costs of inhospital care, and impact on childbearing potential.J Neurol Sci. $2017 \mathrm{Apr}$ 15;375:241-4. https://doi.org/10.1016/j.jns.2017.02.009

38. Ciafaloni E. Myasthenia Gravis and Congenital Myasthenic Syndromes. Continuum (Minneap Minn). 2019 Dec;25(6):1767-84. https://doi.org/10.1212/CON.0000000000000800

39. Gamez J, Salvado M, Casellas M, et al. Intravenous immunoglobulin as monotherapy for myasthenia gravis during pregnancy. J Neurol Sci. 2017 Dec 15;383:118-22. https://doi.org/10.1016/j.jns.2017.10.037

40. Colpo A, Marson P, Pavanello F, et al. Therapeutic apheresis during pregnancy: A single center experience. Transfus Apher Sci. 2019 Oct;58(5):652-8. https://doi.org/10.1016/j.transci.2019.07.009

41. Marson P, Gervasi MT, Tison T, et al. Therapeutic apheresis in pregnancy: General considerations and current practice. Transfus Apher Sci. 2015 Dec;53(3):256-61. https://doi.org/10.1016/j. transci.2015.11.004

42. CoxJL, Koepsell SA, Shunkwiler SM. Therapeutic plasma exchange and pregnancy: A case report and guidelines for performing plasma exchange in a pregnant patient. J Clin Apher. 2017 Jun;32(3):191-5.

43. Lorenzoni PJ, Comerlato EA, Scola RH. Crise miastênica: aspectos clínicos e manejo inicial. In: Teive HAG, Nóvak EM, Lange MC. Condutas em Emergências Neurológicas - diagnóstico e tratamento. 2nd ed. São Paulo(SP): Segmento Farma; 2011. 180-94.

44. Townsel C, Keller R, Johnson K, et al. Seronegative Maternal Ocular Myasthenia Gravis and Delayed Transient Neonatal Myasthenia Gravis. AJP Rep. 2016 Mar;6(1):e133-6. https://doi. org/10.1055/s-0036-1579624

45. Santos E, Braga A, Gabriel D, et al. MuSK myasthenia gravis and pregnancy. Neuromuscul Disord. 2018 Feb;28(2):150-3. https://doi. org/10.1016/j.nmd.2017.11.014

46. Hoff JM, Daltveit AK, Gilhus NE. Asymptomatic myasthenia gravis influences pregnancy and birth. Eur J Neurol. 2004 Aug;11(8):559-62. https://doi.org/10.1111/j.1468-1331.2004.00900.x

47. Riemersma S, Vincent A, Beeson D, et al. Association of arthrogryposis multiplex congenita with maternal antibodies inhibiting fetal acetylcholine receptor function. J Clin Invest. 1996 Nov 15;98(10):2358-63. https://doi.org/10.1172/JCl119048

48. Madi A, Bransburg-Zabary S, Maayan-Metzger A, et al. Tumorassociated and disease-associated autoantibody repertoires in healthy colostrum and maternal and newborn cord sera.J Immunol. 2015 Jun 1;194(11):5272-81. https://doi.org/10.4049/ jimmunol.1402771

49. Durst JK, Rampersad RM. Pregnancy in women with solid-organ transplants: A review. Obstet Gynecol Surv. 2015 Jun;70(6):408-18. https://doi.org/10.1097/0GX.0000000000000194 